\title{
STUDY ON CULEX MOSQUITOES OF BHELUKHEL, BODE AND TATHALI OF BHAKTAPUR DISTRICT, NEPAL
}

\author{
MONICA SHRESTHA ${ }^{1} \bowtie$, ISHAN GAUTAM $^{2}$ AND RANJANA GUPTA $^{1}$
}

${ }^{1}$ Central Department of Zoology, Tribhuvan University, Kirtipur, Kathmandu, Nepal

${ }^{2}$ Natural History Museum, Tribhuvan University, Swayambhu, Kathmandu, Nepal monica_2762@yahoo.com

\section{ABSTRACT}

An entomological study was carried out in Bhelukhel, Bode and Tathali of Bhaktapur district to compare fluctuation in population size of Culex mosquitoes in relation to relative humidity and temperature. Mosquitoes were collected during July-December 2012 around the pig enclosures and cattle sheds by means of dark activated rechargeable CDC light trap. The study resulted $73.41 \%$ of Culex mosquitoes out of the total mosquitoes collected (884). Total eleven species of Culexmosquitoes were recorded namely $C x$. tritaeniorhynchus, $C x$. fuscocephala, Cx. gelidus, Cx. vishnui, Cx. pseudovishnui, Cx. bitaeniorhynchus, Cx. quinquefasciatus, Cx. edwardsi, Cx. hutchnsoni, Cx. whitei and Cx.whitmorei. Distribution of Culexspecies was abundant in July and August. Cx. quinquefasciatus, the principal vector of Lymphaticfilariasis (LF) was recorded to be the most dominant species in all the three sites. Cx. tritaeniorhynchus, the principal Japanese encephalitis (JE) vector was collected in higher number during August from Tathali and Bode site and during July from Bhelukhel site. Significant variation was not observed in abundance of Culex mosquito in three study sites in six different months.

Keywords: Culex, vector, Japanese encephalitis, filariasis, Bhaktapur district

\section{INTRODUCTION}

Mosquitoes the important arthropod vectors are the carrier of some of the most lethal parasitic, bacterial and viral diseases like malaria, filariasis, dengue, encephalitis, yellow fever etc. that claim millions of lives around the world. Mosquito-borne diseases have been considered a serious public health threat as many of people are suffering from this (Gupta et al., 2004).Nepal has also been found vulnerable for different mosquito-borne diseases. Of the total population, about $64.6 \%$ are estimated to be at the risk of mosquito-borne diseases (Joshi et al., 2004). Three diseases namely malaria, Lymphatic filariasis (LF) and Japanese encephalitis (JE) are prevalent in Nepal that causes much mortality and morbidity (Darsie \& Pradhan, 1990). Malaria is transmitted by Anopheles mosquitoes while JE and LF are transmitted primarily by Culex mosquitoes.

The eco-system of Terai belt which is known to be favorable for the breeding of Culex mosquitoes has a humid subtropical climate, warm in the winter and hot in the summer. During monsoon season it receives heavy precipitation, ranging between $180-225 \mathrm{~cm}$ with relative humidity $80 \%-90 \%$ (Joshi, 2004; Joshi et al., 2004). In addition the region has huge rice field land mass which allows the Culex species remains throughout the year. While in mid 
hilly regions like Kathmandu valley,they are active in summer season (Joshi et al., 2004). Cx. quinquefasciatus, Cx. tritaeniorhynchus, Cx. gelidus, Cx. fuscocephala, Cx. bitaeniorhynchus etc. are some of the important culicine mosquitoes that have great public health importance as vector. Of which, $C x$. tritaeniorhynchus and $C x$. quinquefasciatus are suspected to be the principal vector of JE and LF respectively (Darsie \& Pradhan, 1990).

The distribution of culicine species have been reported from different district of Nepal including Bhaktapur district (Sherchandet et al., 2003). Along with the urbanization, human activities, changing climatic pattern and rice field ecosystem are known to be the important factor for distribution of mosquitoes in these areas (Joshi, 2004).

The earlier study conducted in Bhaktapur district by Byanju et al. (2012) revealed the prevalence of good number of Cx. quinquefasciatus in Thapagaun of Jaukhel and Lama tole of Nagarkot, Bhaktapur. Similarly, Shrestha (2011) reported the existence of Cx. tritaeniorhynchus and Cx. gelidus from Balkot Bhaktapur district. Beside this, no clear report is available regarding the distribution of Culex species in the district. Information available on the mosquito fauna, especially Culex is scanty. In view of this, a somewhat broader comprehensive view of species composition of Culex mosquitoes and its prevalence in the district is required to confirm the real situation of mosquito and also for developing an effective control strategy to eliminate the mosquito-borne diseases from the district. Thus the present study was carried out to study species composition of Culex species and its prevalence in Bhaktapur district with special emphasize in Bhelukhel, Bode and Tathali.

\section{MATERIALS AND METHODS}

\section{Study area}

Bhaktapur, the smallest district of Nepal, is situated at $27^{\circ} 36^{\prime}$ to $27^{\circ} 44^{\prime}$ latitude and $85^{\circ} 21^{\prime}$ to $85^{\circ} 32^{\prime}$ longitudes (CBS, 2001). It is situated at west of Bagmati zone and lies about $13 \mathrm{~km}$ eastward of Kathmandu.

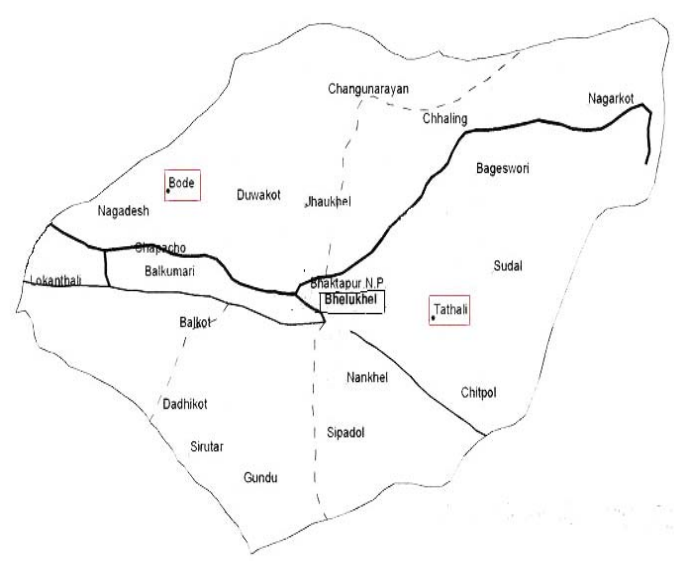

FIG.1. Map showing study sites of Bhaktapur district. 
Bhaktapur is listed as a world heritage by UNESCO for its rich culture, temples and wood, metal and stone artwork and it comprises two municipality viz. Bhaktapur municipality and MadhyapurThimi municipality and sixteen VDCs namely, Bageswori, Balkot, Changunarayan, Chhaling, Chitpol, Dadhikot, Duwakot, Gundu, Jhaukhel, Kautunje, Nagarkot, Nankhel, Sipadol, Sirutar, Sudal, and Tathali. It covers an area of $119 \mathrm{sq} \mathrm{km}$ with an average population of 303,027 in the national census 2011 (CBS, 2012).

Agriculture is the primary occupation of the people. The main crops grown are rice, wheat, maize and different types of vegetable crops. Some of the farmlands are occupied by some local as well as people outside the valley for cattle farming. The climate of the district is sub-tropical cool weather with $75 \%$ annual average humidity. The temperature in general is maximum $32^{\circ} \mathrm{C}$ and minimum $20^{\circ} \mathrm{C}$ and average rainfall is $1400 \mathrm{~mm}$ most of which falls during June to August.

Three sites namely Bhelukheltole of Bhaktapur municipality, Bode tole of MadhyapurThimi municipality and Tathali VDC were selected as thesurvey sites to study species composition, abundance and prevalence of Culex mosquitoes. The sites were selected on the basis of presence of pig rearing, practices of traditional cattle shading, paddy cultivation, and presence of mosquito breeding sites.

\section{Entomological survey}

To assess the prevalence and fluctuation, mosquitoes were collected twice a month in each site throughout the month in July to December 2012. Mosquitoes were collected using dark activated rechargeable CDC light trap (Bio Quip Products, Inc. 2321 E Glaowick St. Rancho Dominguez, CA 90220, USA) fitted with double ring fine mesh collection bags, specifically, one light trap was placed outside houses within the same compound per village at dusk and was collected at dawn the next day. The light trap was fixed at about $5 \mathrm{ft}$. above the ground. The light trap was turned on overnight. Samples were collected in the morning after each night.

The screened bag from the light trap was removed and the mosquitoes were anesthetized with the help of ethyl acetate. These mosquitoes were then transported to the Tribhuvan University, Natural History Museum, Swayambhu for identification. All the sampled mosquitoes were morphologically studied and identified to the species level by using standard key by Darsie \& Pradhan (1990).

\section{Meteorological data}

The relative humidity and average temperature for the period of the study was recorded by means of Thermo-hygrometer.

\section{Data analysis}

Recorded meteorological data and entomological data during the six month of study period were entered in excel and the variation in the number of Culex species between different study sites and month wise survey was analyzed by using two- way ANOVA table. 


\section{RESULTS}

A total of 884 mosquitoes belonging to 6 genera and 21 species were collected. Culex species constituted $73.41 \%$ (649) of the total, of which $65.46 \%$ were recorded from Bode and $18.55 \%$ and $15.99 \%$ were recorded from Bhelukhel and Tathali respectively (fig.2).

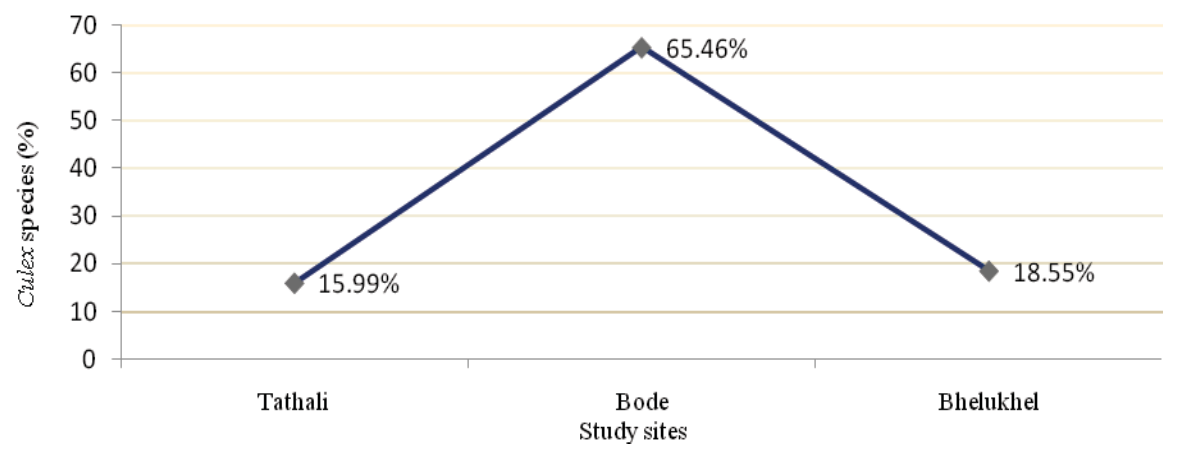

FIG.2. Culex species collected during study period.

Monthwise prevalence of Culex species in Bhelukhel is shown in table 1. Of the total 121 mosquitoes collected, highest population density was recorded in July (39.01\%). During this month $C x$. quinquefasciatus contributed a dominant species comprising $17.89 \%(22 / 121)$. $C x$. tritaeniorhynchus recorded to be the second most abundant species constituting $6.5 \%$ (8/121). Other species Cx. bitaeniorhynchus, Cx. vishnui and Cx.fuscocephala constituted $4.88 \%, 3.25 \%$ and $3.25 \%$ of 121 respectively. Second highest density was recorded in August. During this period $C x$. bitaeniorhynchus showed a tall peak with $6.5 \%(8 / 121)$. Among the all species collected, $C x$. fuscocephala was found in every month except December, with its peak abundance in September (5.7\%). No mosquito was collected in December.

TABLE 1. Monthwise percent abundance of Culex species in Bhelukhel.

\begin{tabular}{|l|r|r|r|r|r|r|}
\hline Mosquito species & \multicolumn{1}{c}{ July } & \multicolumn{2}{|c|}{ August September October November December } \\
\hline Cx. tritaeniorhynchus & 6.5 & 1.63 & 1.63 & 0 & 0 & 0 \\
\hline Cx. bitaeniorhynchus & 4.88 & 6.5 & 4.88 & 0 & 1.63 & 0 \\
\hline Cx. vishnui & 3.25 & 4.1 & 1.63 & 0 & 0 & 0 \\
\hline Cx. pseudovishnui & 0.8 & 3.25 & 3.25 & 0 & 0 & 0 \\
\hline Cx. gelidus & 0 & 3.25 & 1.63 & 0 & 0.8 & 0 \\
\hline Cx. quinquefasciatus & 17.89 & 3.25 & 1.63 & 0 & 1.63 & 0 \\
\hline Cx. fuscocephala & 3.25 & 4.88 & 5.7 & 0.8 & 0.8 & 0 \\
\hline Cx. edwardsi & 2.44 & 1.63 & 4.1 & 0 & 0 & 0 \\
\hline Cx. whitmorei & 0 & 0 & 1.63 & 0 & 0.8 & 0 \\
\hline Total & 39.01 & 28.49 & 26.08 & 0.8 & 5.66 & 0 \\
\hline
\end{tabular}


TABLE 2. Monthwise percent abundance of Culex species in Bode.

\begin{tabular}{|c|c|c|c|c|c|c|}
\hline & July & August & September & October & November & December \\
\hline Cx.tritaeniorhynchs & 1.21 & 4.91 & 1.23 & 0 & 0 & 0 \\
\hline Cx.bitaeniorhynchus & 5.39 & 11.17 & 0.34 & 0 & 0 & 0 \\
\hline Cx. vishnui & 1.94 & 14.56 & 0.68 & 0 & 0 & 0 \\
\hline Cx. pseudovishnui & 1.94 & 5.8 & 1.17 & 0 & 0 & 0 \\
\hline Cx. gelidus & 1.94 & 2.18 & 0 & 0 & 0 & 0 \\
\hline Cx.quinquefasciatus & 2.7 & 17.48 & 7.7 & 0 & 0 & 0.2 \\
\hline Cx. fuscocephala & 1.94 & 9.22 & 3.35 & 0 & 0.2 & 0 \\
\hline Cx. edwardsi & 1.94 & 0 & 0.22 & 0 & 0 & 0 \\
\hline Cx. hutchinsoni & 0.2 & 0.23 & 0 & 0 & 0 & 0 \\
\hline Total & 19.2 & 65.55 & 14.69 & 0 & 0.2 & 0.2 \\
\hline
\end{tabular}

Table 2 lists the month wise percent abundance of Culex species in Bode. The highest number of mosquitoes was collected in August. Of the total 421 Culex mosquitoes collected during that period comprised $17.48 \%$ Cx. quinquefasciatus, $14.56 \%$ Cx. vishnui, $11.17 \%$ Cx. bitaeniorhynchus, 9.22\% Cx. fuscocephala and 4.91\% Cx. tritaeniorhynchus. The second highest numbers of mosquitoes were collected in July. Cx. bitaeniorhynchus was the predominant species collected during July comprising 5.39\% (14/421), Cx. tritaeniorhynchus constituted $0.57 \%$ (5/421). Each of $C x$. vishnui, Cx. pseudovishnui, $C x$. gelidus, $C x$. quinquefasciatusand $C x$. fuscocephala constituted nearly $0.9 \%$ of the total 421 . The numbers of mosquitoes were gradually decreased from September.

TABLE 3. Monthwise percent abundance of Culex species in Tathali VDC.

\begin{tabular}{|c|c|c|c|c|c|c|}
\hline Mosquito species & July & August & September & October & November & December \\
\hline Cx. tritaeniorhynchus & 0 & 0.95 & 0 & 0 & 0 & 0 \\
\hline Cx. bitaeniorhynchus & 2.86 & 1.9 & 0 & 3.81 & 0 & 0 \\
\hline Cx. vishnui & 2.86 & 0 & 0 & 0 & 0 & 0 \\
\hline Cx. gelidus & 0 & 0 & 0 & 0 & 1.95 & 0 \\
\hline Cx. quinquefasciatus & 42.85 & 7.62 & 4.76 & 0.95 & 1.95 & 0 \\
\hline Cx. fuscocephala & 12.38 & 3.81 & 0.95 & 0 & 0 & 0 \\
\hline Cx. edwardsi & 5.71 & 0.95 & 0.95 & 0 & 0 & 0 \\
\hline Cx. hutchinsoni & 0.95 & 0 & 0 & 0 & 0 & 0 \\
\hline Cx. whitei & 1.9 & 0 & 0 & 0 & 0 & 0 \\
\hline Total & 69.51 & 15.23 & 6.66 & 4.76 & 3.9 & 0 \\
\hline
\end{tabular}


Monthwise percent abundance of Culex species in Tathali (table 3) shows that $C x$. quinquefasciatus was the dominant species and was collected in every month of study period except December with its highest peak in July (42.85\%). Cx. fuscocephala was the second dominant species. During July each of $C x$. vishnui and $C x$. bitaeniorhynchus constituted $2.86 \%$ of the total. Cx. tritaeniorhynchus was collected only in August and constituted $0.95 \%(1 / 105)$. Similarly, Cx. gelidus was found only in November comprising $1.95 \%(2 / 105)$. No specimen was collected in December.Significant variation was not observed in Culex species abundance in three study sites in six different months of study period.

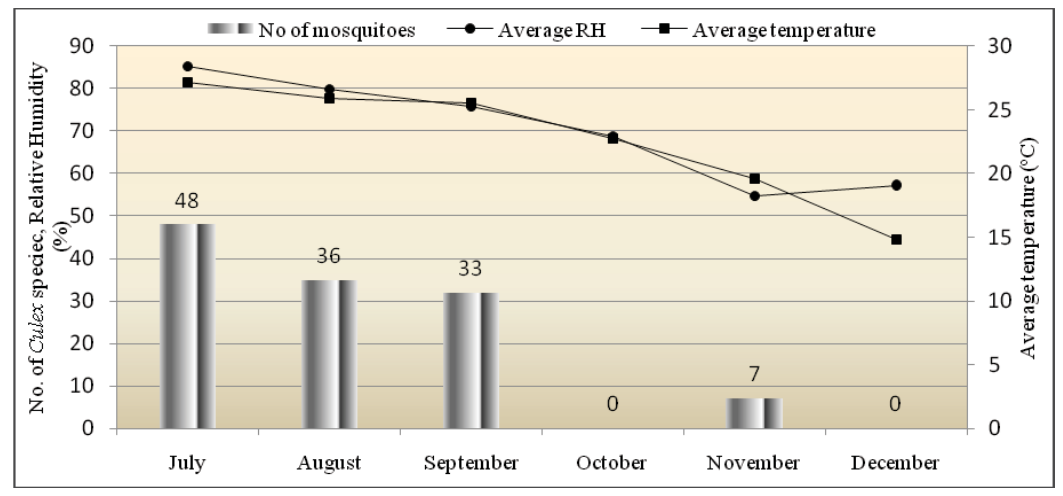

FIG. 3. Culex species in relation to average temperature and relative humidity in Bhelukhel.

A total of 48 Culex species were collected in July from Bhelukhel. At that time the average temperature was recorded as $27.15^{\circ} \mathrm{C}$ and $\mathrm{RH}$ as $85.25 \%$. In the month of October the mosquito number abruptly decreased to 0 when the average temperature and $\mathrm{RH}$ was recorded to be $22.73^{\circ} \mathrm{C}$ and $68.83 \%$ respectively. The mosquitoes were recollected in November when the average temperature and average $\mathrm{RH}$ was recorded to be $19.57^{\circ} \mathrm{C}$ and $54.75 \%$ respectively (fig.3).

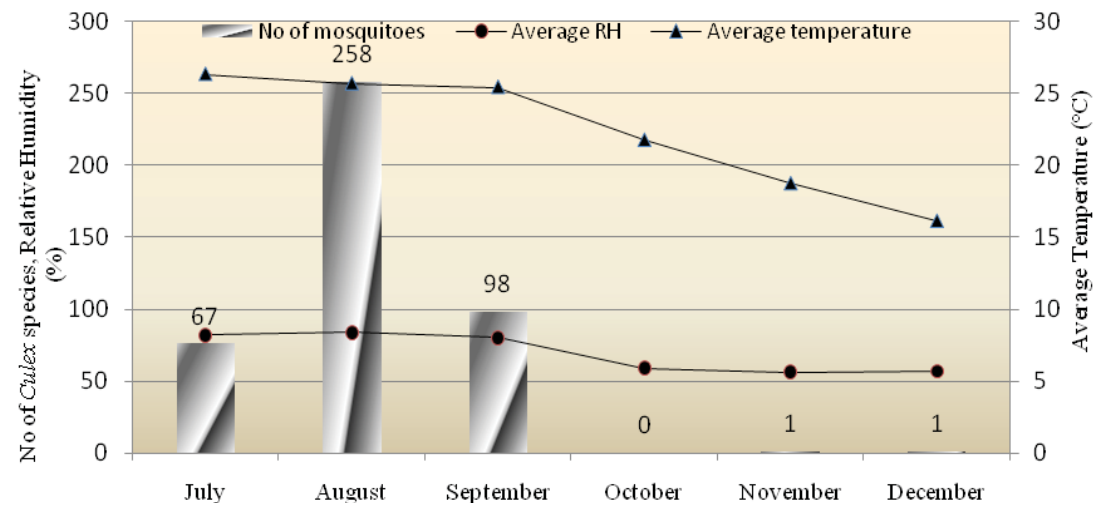

FIG. 4. Culex species in relation to average temperature and relative humidity in Bode. 
The prevalence of Culex species in relation to average temperature and Relative Humidity in Bode (fig.4) shows that the maximum number of Culex species reached to 258 in August when the average temperature was recorded as $25.69^{\circ} \mathrm{C}$ with average Relative Humidity $83.75 \%$. The average temperature and average $\mathrm{RH}$ during October was recorded as $21.78^{\circ} \mathrm{C}$ and $59.2 \%$ respectively and no mosquito was collected during this month. As shown in fig. 5 , where the distribution of Culex species in relation to average temperature and Relative Humidity in Tathali is presented, the maximum number of 73 Culexspecies was collected in July. The average temperature at that time was recorded as $25.66^{\circ} \mathrm{C}$ and average Relative Humidity $86.38 \%$. No Culex species was found in December when the temperature was $13.94^{\circ} \mathrm{C}$ and relative humidity was $56.73 \%$.

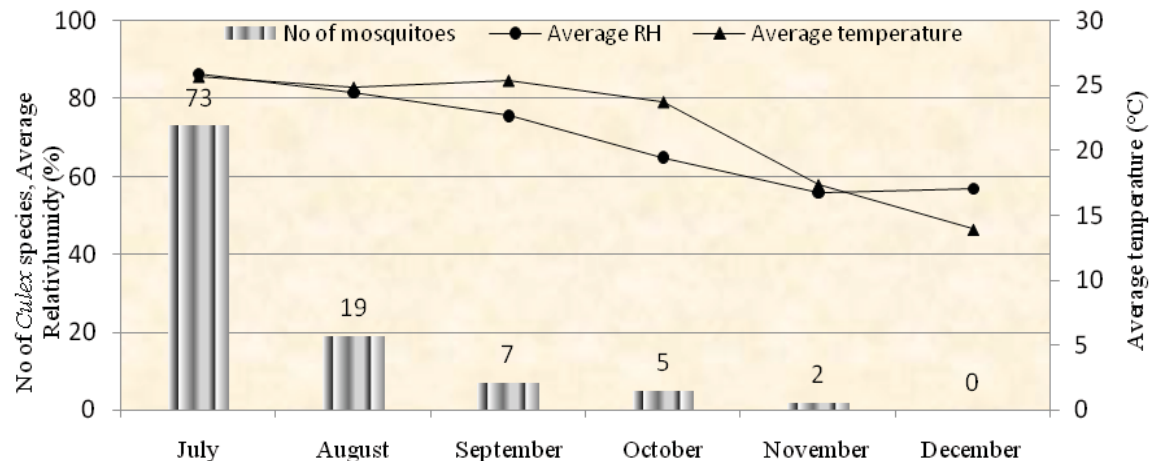

FIG. 5. Culex species in relation to average temperature and relative humidity in Tathali.

The distribution of Culex mosquitoes were highest in July-August (wet and rainy season) and found to be the lowest in October- December.

\section{DISCUSSION}

The study of mosquito population in Kathmandu valley revealed the similar result (Shrestha, 2011). The present study found $C x$. quinquefasciatus, the principal vector of $L F$, as a dominant species. Though the species is known as poor vector of JE, few isolates of JE virus have been made from this species in India and Vietnam (Sirivanakarn, 1976). It constitutes $6.89 \%$ in Tathali, $16.75 \%$ in Bode and $3.40 \%$ in Bhelukhel. The species was found maximum in July and August. The result can be compared with a study conducted by Byanju et al. (2012) which reported the highest population density of $C x$. quinquefasciatus in July and lowest in September.Neupane et al. (2009) reported the similar result in Chitwan district. Cx. tritaeniorhynchus, the principal JE vector of Nepal, whichconsisted $3.74 \%$ of the total collection was recorded in higher density from Bode in August. The species showed its tall peak during the paddy cultivation period in Kathmandu valley (Shrestha, 2011).

The study conducted in Gorakhpur, India also found rice fields contributing towards the building up of population density of JE vectors (Kanojia et al., 2003). House spraying with 
residual insecticides, elimination of breeding sites and intermittent paddy irrigation may help in controlling larval population of Cx. tritaeniorhynchus (Kanojia et al., 2003). Cx. gelidus which has also been incriminated as a important JE vector in Nepal was recorded with good number from Bode $(n=19)$ and Bhelukhel $(n=16)$ but relatively fewer was recorded from Tathali $(n=1)$. All three sites represent large proportion of rice cultivation and few numbers of piggeries. This species breed in habitat like cow dung pit, ground pools containing much weeds, marshy tracts etc (Gubler et al., 1989).

Cx. pseudovisnui, Cx. fuscocephala, Cx. bitaeniorhychus and Cx. vishnui was also found in appreciable density between July, August and September. These species are known to breed in large ground pools always filled with dense mass of filamentous green algae (Sirivanakarn ,1976). Other Culex species viz. Cx. edwardsi, Cx. thileria, Cx. hutchinsoni, Cx. whitei andCx. whitmorei formed $10.41 \%$ of the total collected mosquitoes. Almost all individual species showed a rapid decline in the population from July to December as average temperature falls from $26.38^{\circ} \mathrm{C}$ to $14.97^{\circ} \mathrm{C}$ and average $\mathrm{RH}$ from $84.46 \%$ to $56.98 \%$. From the statistical analysis, variable vector mosquito distribution was recorded in three study sites. Similar with the present study which showed no significant variation in Culexspecies abundance in three study sites in six different months, a study carried out in Jaukhel and Nagarkot of Bhaktapur district showed the insignificant monthwise variation of Cx. quinquefasciatus density (Byanju et al., 2013).

The highest number of mosquito was collected in July and August when the average temperature was recorded between $25.65^{\circ} \mathrm{C}-26^{\circ} \mathrm{C}$ with average $\mathrm{RH} 79.10 \%-86.69 \%$ which was similar to the study carried out by Joo \& Kang (1992) who reported the highest average mosquito catch in night was July, when the temperature was between $18.6^{\circ} \mathrm{C}-34.8^{\circ} \mathrm{C}$ and the average RH 59\%.-76\%. Significant relation was not observed between density of Culex species with temperature and relative humidity. In opposite to this study, Neupane et al. (2009) showed positive correlation density of Culex with temperature. The pattern of rainfall, paddy ecosystem along with temperature and humidity affects larval breeding habit and distribution of mosquitoes (Arunanchalum et al., 2004; Gubler et al., 1989). The present study gives the information on the species composition, relative abundance and fluctuation of Culex species in the study area that provides the baseline data necessary for concerned health workers. Thespeciescollected from three sitesindicates the risk of area with regards to mosquito-borne diseases including JE and LF. The study shows the need of regular monitoring of mosquito in the district to find out the actual situationof mosquito and to inhibit the forthcoming disease epidemics.

\section{AKNOWLEDGEMENS}

The authors acknowledge to the local residents of Bhelukhel, Bode and Tathali VDC, for their permission to conduct light trap operation for six months in the research.

\section{REFERENCES}

ARUNACHALAM, N; SAMUEL, P P; HIRIYAN, J; RAJENDRAN, R; DASH, A P (2004) Short report: observations on the multiple feeding behavior of Culex tritaeniorhynchus (Diptera: Culicidae) the vector of Japanese encephalitis in Kerala in Southern India. American Journal of Tropical Medicine and Hygiene 72(2):198-200.

BYANJU, R; GAUTAM, I; ARYAL, M; K C, A; SHRESTHA, H N; DHIMAL, M (2013). Adult density of Culex 
quinquefasciatus Say, filarial vector in Thapa gaun, Jhaukhel and Lama Tole, Nagarkot VDC, Bhaktapur district. Nepal Journal of Science and Technology 14(1):185-194.

CBS (2001) Central Bureau of Statistics, Government of Nepal National Planning Commissiom Secretariat, Kathmandu, Nepal.

CBS (2012) Central Bureau of Statistics, Government of Nepal National Planning Commissiom Secretariat. National Population and Housing Census 2011 (National report). Volume 02, NPHC 2011.

DARSIE, R F; PRADHAN, S P (1990) The mosquitoes of Nepal: their identification, distribution and biology. Journal of American Mosquito Control Association 22:69-130.

GUBLER, D J; MITCHEL, C J; LACEY, LA (1989) Japanese encephalitis in Nepal: recommendation for short and long term control. Agency for international development, Washington DC Report No. AR 115(4):1-36.

GUPTA, P; KUMAR, P; AGARWAL, O P (2004) Knowledge, attitude and practices related to dengue in rural and slum areas of Delhi after the dengue epidemic of 1996. Journal of Communicable Diseases 30(2): 107-112.

JOO, C Y; KANG, G T (1992) Epidemio-entomological survey on malaria vector mosquitoes in Kyongbuk, Korea. The Korean Journal of Parasitology 30(4): 329-340.

JOSHI, Y R (2004) Epidemiological study of Japanese encephalitis in Kanchanpur district during outbreak season. M.Sc. dissertation, Central Department of Zoology, Tribhuvan University, Kathmandu, Nepal.

JOSHI, A B; BANJARA, M R.; BHATTA, L R; WIERZBA, T (2004) A five year retrospective review: status trend of Japanese encephalitis epidemics in Nepal. Journal of Nepal Health Research Council 2(1): 59-64.

KANOJIA, P C; SHETTY; GEEVARGHESW, G (2003) A long-term study on vector abundance and seasonal prevalence In relation to the occurrence of Japanese encephalitis in Gorakhpur district, Uttar Pradesh. Indian Journal of Medical Research 117:104-110.

NEUPANE, V D; GAUTAM, I; TAMRAKAR , A S; SHRESTHA, S R (2009) Seasonal distribution of adult Culex mosquitoes in Chitwan district, Nepal. Journal of Institute of Science Technology 17: 103-116.

SHERCHAN, J B; OBSOMER, V; THAKUR, G D; MARCHEL, H (2003) Mapping of lymphatic filariasis in Nepal. Filarial Journal 2: 7.

SHRESTHA, H N (2011) Abundance of Culex tritaeniorhynchus Giles and Culex gelidus Theobald in Kathmandu valley, Nepal. M.Sc. dissertation, Central Department of Zoology, Tribhuvan University, Kathmandu, Nepal.

SIRIVANAKARN, S (1976) Medical entomology studies-III. A revision of the subgenus Culex in the Oriental Region (Diptera: Culicidae). American Entomological Institute (Ann Arbor),12: 1-272. 